\title{
Septic arthritis in children
}

\author{
L'artrite settica in età pediatrica
}

V. Riccio, ${ }^{1}$ I. Riccio, ${ }^{1}$ G. Porpora,${ }^{1}$ D. Riccardi, ${ }^{1}$ G. Riccardi ${ }^{1}$

Key words: septic arthritis, childhood

\begin{abstract}
Osteoarticular infections are a form of diagnostic and therapeutic emergency in infants and children, even if relatively rare.

Despite decades of experience with different protocols, and multiple clinical trials, today it is still difficult to determine what kind of antibiotics is really effective, what kind of associations are required, which is the optimal time range of a treatment, when and on which subjects to base the transition from a parenteral treatment to an oral one.

Current philosophy aims more and more at reducing hospitalization and costs, and wants to decrease the discomfort in the family. The purpose of these guidelines is to promote a reasoned clinical and therapeutic approach, in a context of diagnostic probabilities that offer the best chance of success in reducing hospitalization with a rapid transition to an oral treatment, and then outpatient, and thus educing totally the processing time.
\end{abstract}

\section{Introduction}

Osteoarticular infections are a form of diagnostic and therapeutic emergency in infants and children, even if relatively rare. Without a precocious and properly aimed antibiotic treatment there is the risk of a local and general septic expansion, and the possibility of some serious articular outcomes. The more the articular involvement is precocious, the more we can run risks of some adverse outcomes.

\footnotetext{
1 Department of Orthopaedics Traumatology Rehabilitation and Plastic-Surgery, Second University of Naples, Italy

Indirizzo per la corrispondenza (Corresponding author):

Prof. V. Riccio

Via L. De Crecchio, 4 - 80100 Naples, Italy

e-mail: vincenzo.riccio@unina2.it

Tel: +390815665535 Fax: +39081459914
}

Despite decades of experience with different protocols, and multiple clinical trials, today it is still difficult to determine what kind of antibiotics is really effective, what kind of associations are required, which is the optimal time range of a treatment, when and on which subjects to base the transition from a parenteral treatment to an oral one.

In literature there are only a few studies reporting the incidence of septic arthritis in childhood (S.A.). $9,14,27,39,40$

As for the frequency, based on age, Lechevalier reports that AS is present for $63 \%$ to $<5$ years, $49 \%<3$ years and for $31 \%<2$ years; on the contrary Valdiserri ${ }^{38}$ for $80 \%<4$ years and $50<1$ year.

The most frequently affected sites are knee and hip with a variable incidence, according to various authors9 13, 25, 27, 30, 38, 39, 40 (Table 1). The pathogenesis of SA has been not yet totally clarified, despite the numerous histological and histochemical studies (Schenk, ${ }^{29}$ Whallen, ${ }^{42}$ Tudisco, Ippolito, and others ${ }^{36}$ ). There were some hyphothesis concerning the vascular tissular osteo-articular anatomy during the period of children's growth, the main mechanism of inoculation, the virulence of the pathogen agent, the epidemiology in nursing infants and young children, bacteremia and, finally, concerning the role of trauma during this age. ${ }^{32}$ In infants and young children the location is typically epiphyseal and, while in older children metaphyseal. These different locations are the consequence of the special blood vessels at the extremity of long bones. Thanks to their studies concerning the vascularization of the proximal femoral epiphysis, Trueta ${ }^{31-35}$ and Chung ${ }^{8}$ show how, before the appearance of the proximal epiphyseal ossification nucleus, epiphyseal vessels originate directly from metaphysis, while after the appearance of the ossification nucleus, a vascular autonomous epiphyseal net develops, while vascular vessels disappear. ${ }^{35}$ Metaphysis of long bones, in

EPIDEMIOLOGY OF SEPTIC ARTHRITIS

\begin{tabular}{ll} 
Frequency of septic arthritis & \\
\hline Stott 2001 & $0,06 / 1.000 /$ year \\
\hline Wang 2003 & $0,05 / 1.000 /$ year \\
\hline Rasmont 2008 & $0,12 / 1.000 /$ year \\
\hline Lechevalier 1996 & $0,63 / 1.000 /$ year \\
\hline
\end{tabular}


young children and infants, is almost entirely made up of spongious bone extremely rich in vessels tissue, with fetal-type circulation and voluminous capillary loops and large venous lakes, that are connected with the epiphyseal .

An infection of blood in the first months of life may propagate to the epiphyseal cartilage and quickly destroy the nucleus, whose subsequent development may be definitely compromised. Therefore acute arthritis in infants constitutes a separate chapter because of its anatomical peculiarities. For example the capsule, in the hip, is eccentrically inserted and the ephyseal plate, and a part of the metaphysis, are intra-articular. In this way an infectious process, localized in the metaphysis, may spread to the epiphysis and become intra-articular or may invade directly the articular environment.

\begin{tabular}{ll}
\hline Table 2 & \\
& CLINICAL SIGNS AND RELATIVE PERCENTAGE \\
\hline Fever & $40 \%-90 \%$ \\
\hline Articular pain & $81 \%-93 \%$ \\
\hline Hydrarthrus & $72 \%-85 \%$ \\
\hline Limping (knee, hip) & $43 \%$ \\
\hline Painful limitations of joint mobility & $64 \%-75 \%$ \\
\hline Pseudoparalysis & $90 \%$ newborn \\
\hline Flush & $86 \%$ \\
\hline Erythema & $55 \%$ \\
\hline
\end{tabular}

\begin{tabular}{lc}
\hline Table 3 & \\
& BLOOD PARAMETERS \\
\hline Marked polynucleosys +++ & $40 \%$ \\
\hline ESR +++ & $89 \%$ \\
\hline PCR +++ & $89 \%$ \\
\hline Prealbumin & \\
\hline
\end{tabular}

Table 4

INTRAVENOUS ANTIBIOTICS TREATMENT

Empirical treatment using broad spectrum intravenous antibiotics (Gram positives + Gram negatives)

\begin{tabular}{ll}
\hline Monotherapy & Association \\
\hline beta-lactam (Cloxacillin) & Amoxicillin + Clavulanic acid \\
\hline Cephalosporin II & $\begin{array}{l}\text { Vancomycin + Rifampicin } \\
\text { (for MRSA) }\end{array}$ \\
\hline Cefamandolo 0 Cefurossima) & $\begin{array}{l}\text { Monotherapy + Gentamicin } \\
\text { Cephalosporin III }\end{array}$ \\
(Ceftriaxone) & (age $<3$ months) \\
\hline
\end{tabular}

\begin{tabular}{lll}
\hline Table 5 & & \\
& MOST COMMON ISOLATED GERMS & \\
& Newborn & Children \\
\hline Stafilococcus Aureus & +++ & +++ \\
\hline Stafilococcus Coag neg & - & ++ \\
\hline Stafilococcus Methicillin resistant & \multicolumn{1}{c}{ Acquired in community } \\
\hline Streptococcus pneumonia & ++ & - \\
\hline Haemophilus influenza b & - & ++ \\
\hline Group b Streptococci & + & ++ \\
\hline Pseudomonas aeruginosa & - & ++ \\
\hline Escherichia Coli & + & - \\
\hline Kighella Kingae & - & +++ \\
\hline Enterobacter & + & + \\
\hline Salmonellae & + & ++ \\
\hline
\end{tabular}

The immuno-biological fragility of newborn and infants is a facilitation factor.

The carrier of germs is essentially hematogenous, rarely cutaneous or by maternal infection.

Guidelines (Table 1): It is well known that AS heals in most cases with antibiotic therapy, but an antibiotic treatment should be implemented in high doses, intravenously and for prolonged periods (4-8 weeks). ${ }^{16}$ Current philosophy aims more and more at reducing hospitalization and costs, and wants to decrease the discomfort in the family. The analysis of recent literature shows us that we can rationalize the therapeutic approach in infants and children to osteo-arthritis through the help of what is current knowledge in epidemiology, bacterial sensitivity to major antibiotics, while the most recent clinical results have shown the same efficacy of a parenteral antibiotic therapy longer or inferior to the duration of 7 days. ${ }^{17}$ Current guidelines refer to common acute osteo-articular infections, not complicated in healthy infants and children, of hematogenous origin, with usual not well-identified bacteria or, as it often happens, not identified, excluding unusual germs of complex inoculation routes such as post-operative infections, or direct inoculation after bites and trauma, in chronic or complicated forms, or special situations such as severe host immunocompromission. ${ }^{13,16}$ The purpose of these guidelines is to promote a reasoned clinical and therapeutic approach, in a context of diagnostic probabilities that offer the best chance of success in reducing hospitalization with a rapid transition to an oral treatment, and then outpatient, and thus educing totally the processing time.

These recommendations are based on these essential points:

Rapidity in diagnosis

Knowledge of commonly involved bacteria, and their response to antibiotics

The results of clinical studies published in literature

The evaluation of the effectiveness of general and local treatment. ${ }^{13}$, 20

\section{Materials and methods}

In front of a baby or a child with a suspected septic arthritis, the criteria for a correct diagnosis are clinical, laboratory and instrumental.

The clinical data are represented by fever, articular pain, hydrarthrus, painful limitations of joint mobility, pain on palpation of the limb, pseudoparalysis of the interested limb in newborn (Table 2). ${ }^{5}$

In blood parameters (Table 3) is always present:

marked polynucleosys

ESR level greatly increased

PCR level already and early increased. This parameter is crucial to follow the evolution of the infection: its decrease is indicative of the efficacy of the therapy; in absence of a decrease, a modification of the antibiotic therapy is required. Normalization is not a sufficient 
criterion of recovery. 6,7

Finally it may be useful to test the Prealbumin to study the nutritional status of the newborn. In Table 3 there are reported the percentages of positive results, keeping in mind that the association of at least two clinical and blood signs gives a $91 \%$ in sensitivity and a $95 \%$ in specificity. ${ }^{10,30}$

At the same time before moving to a deeper bacteriological understanding it may be useful to perform an ultrasound instrumental examination. Ultrasonography increases in importance because of its safety and repeatability, even though it requires an experienced operator for its performance. Ultrasound may influence the presence and type of endoarticular collection (Fig. 1) and permits to follow the evolution of the infection in the newborn and to understand the damage to the epiphyseal nuclei, especially that of the upper femur. ${ }^{15,19,24,28}$ At a metaphyseal level it shows the presence of eventual subperiosteal abscesses. Later on it shows the periosteum far from the bone with a slight intermediate zone for the presence of an anechoic abscess. It finally allows to guide properly, specially in the less superficial areas, the evacuating puncture.

In special cases a bone scan can be performed but its use is still very controversial because some false negatives have been described that can be interpreted as indicative of a more serious index due to some important local circulatory disorders, that prevent the penetration of the tracer. ${ }^{1}$

After ultrasound it becomes essential to isolate the responsible germ of the infection.

It can be done through:

systematic peripheral sampling (navel, urine, ENT)

blood cultures (positive in 40-60\% of cases)

evacuating puncture: it is practiced in emergency and permits to collect liquid for cell culture and to decompress the joint. The germ is isolated in only $50-60 \%$ of cases.

An evacuating puncture must be repeated every 48 hours to evacuate the joint and to decrease the endoarticular pressure and doing like this the buffering effect it can have on the capsular vessels, with a possible consequent epiphyseal necrosis. It also allows to inject an antibiotic directly into the joints.

However, if the ultrasound shows the presence of pus in the articulation, we must effect an arthrotomy above all in neonates and young children, as most authors suggest.

In this way it can be done an articular wash too, that can get away all the articular bacterial toxic products that cause a fall in the rate of collagen necessary to maintain a good mechanical strength of the cartilage.

In more recent years arthroscopy is being considerated more and more useful, especially for knee and shoulder because it grants a more rapid functional recovery. Postoperatively we need to leave a redon-drainage, and also to practice a restraint for analgesic aim. ${ }^{11}$ After articular lavage, we can start an empirical treatment using broad spectrum intravenous antibiotics (Table 4) while expecting to know the responsible germ. It should be noted that if we start an antibiotic treatment late the risks for serious possible osteo-cartilaginous damages are higher., ${ }^{37}$

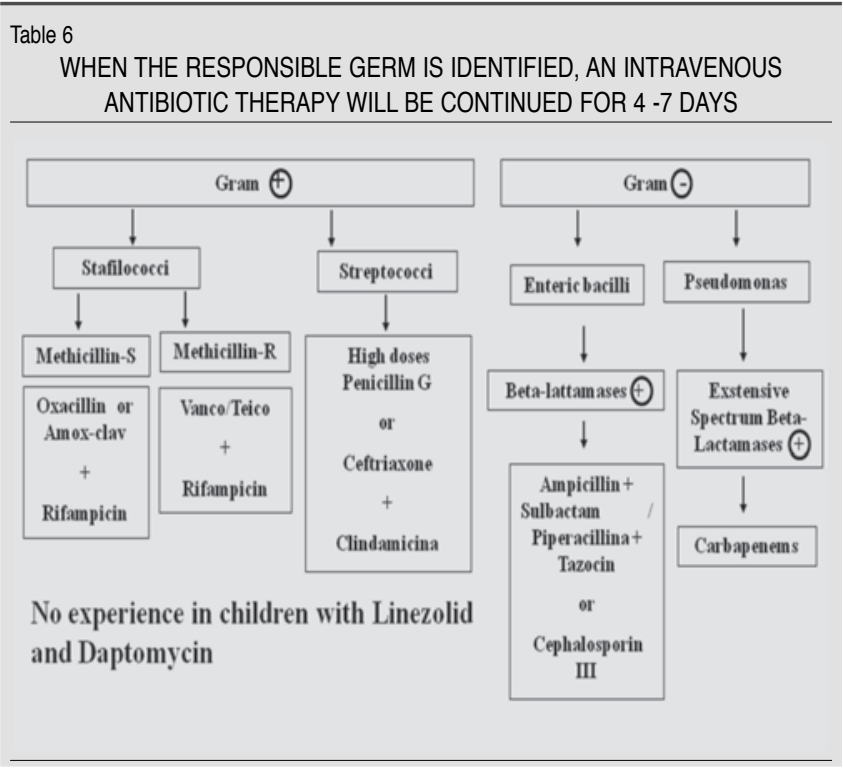

Table 7

\section{WHEN THE GERM IS NOT ISOLATED}

Not isolated germs

we will continue an intravenous broad-spectrum antibiotic therapy enhanced or modified if we don't get a positive response

\begin{tabular}{ll}
\hline Monotherapy & Association \\
\hline beta-lactam (Cloxacillin) & Amoxicillin + Clavulanic acid \\
\hline Cephalosporin II & Vancomycin + Rifampicin \\
(Cefamandolo o Cefurossima) & (for MRSA) \\
\hline Cephalosporin III & Monotherapy + Gentamicin \\
(Ceftriaxone) & (age $<3$ months) \\
\hline
\end{tabular}

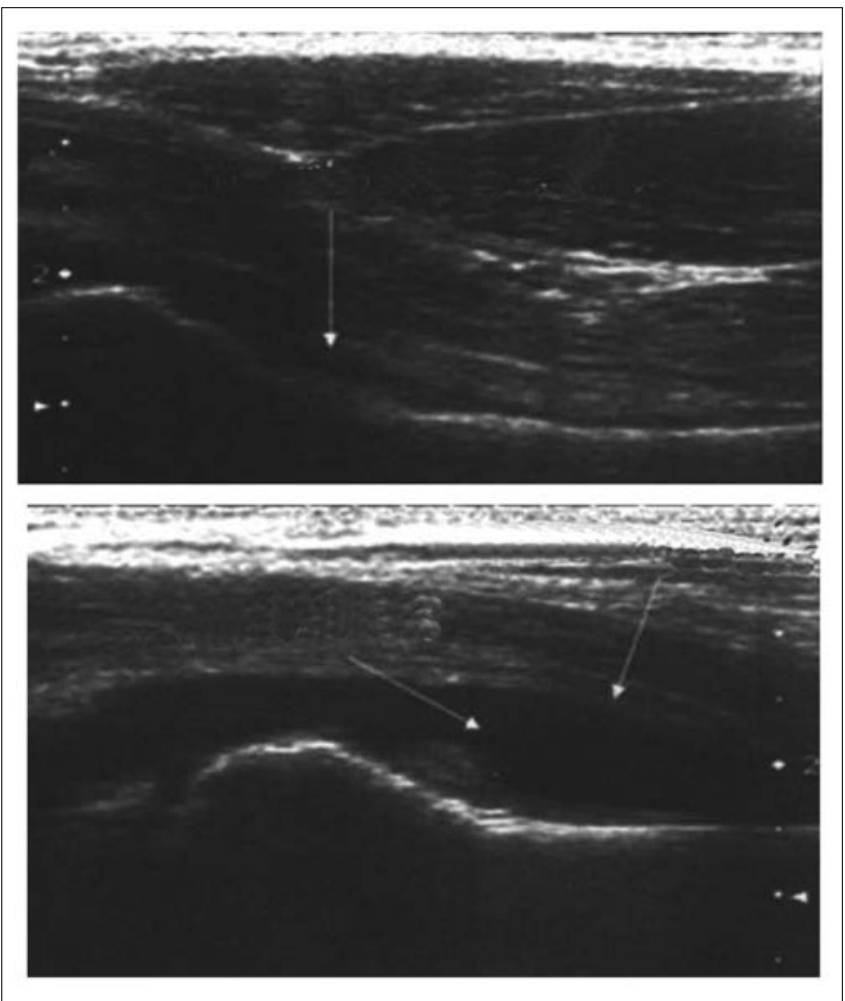

Figure 1.

the image above shows a normal hip ultrasound the lower showing the presence of an advance 
The most common isolated germs are:

Staphylococcus aureus in $70 \%$ of cases there is now a consequence of a strain of multidrug-resistant nosocomial infection that is the source of the most important osteo-cartilaginous destruction.

Beta-hemolytic streptococcus group B in $10-25 \%$ of cases seems to increase today, but the clinical and biological frame is good and with a benign functional prognosis.

the Haemophilus influenzae in $10-15 \%$ of cases, often associated with an infection of the airways from 3 months of age.

Pneumococcus more rarely than haemophilus but with the same characteristics

Table 8
THE RISK FACTORS
Age $<1$ year
Location: Hip, Knee and elbow
The aggressiveness of the germ
The beginning of treatment ( $>4$ days of infection)
Serology ++++

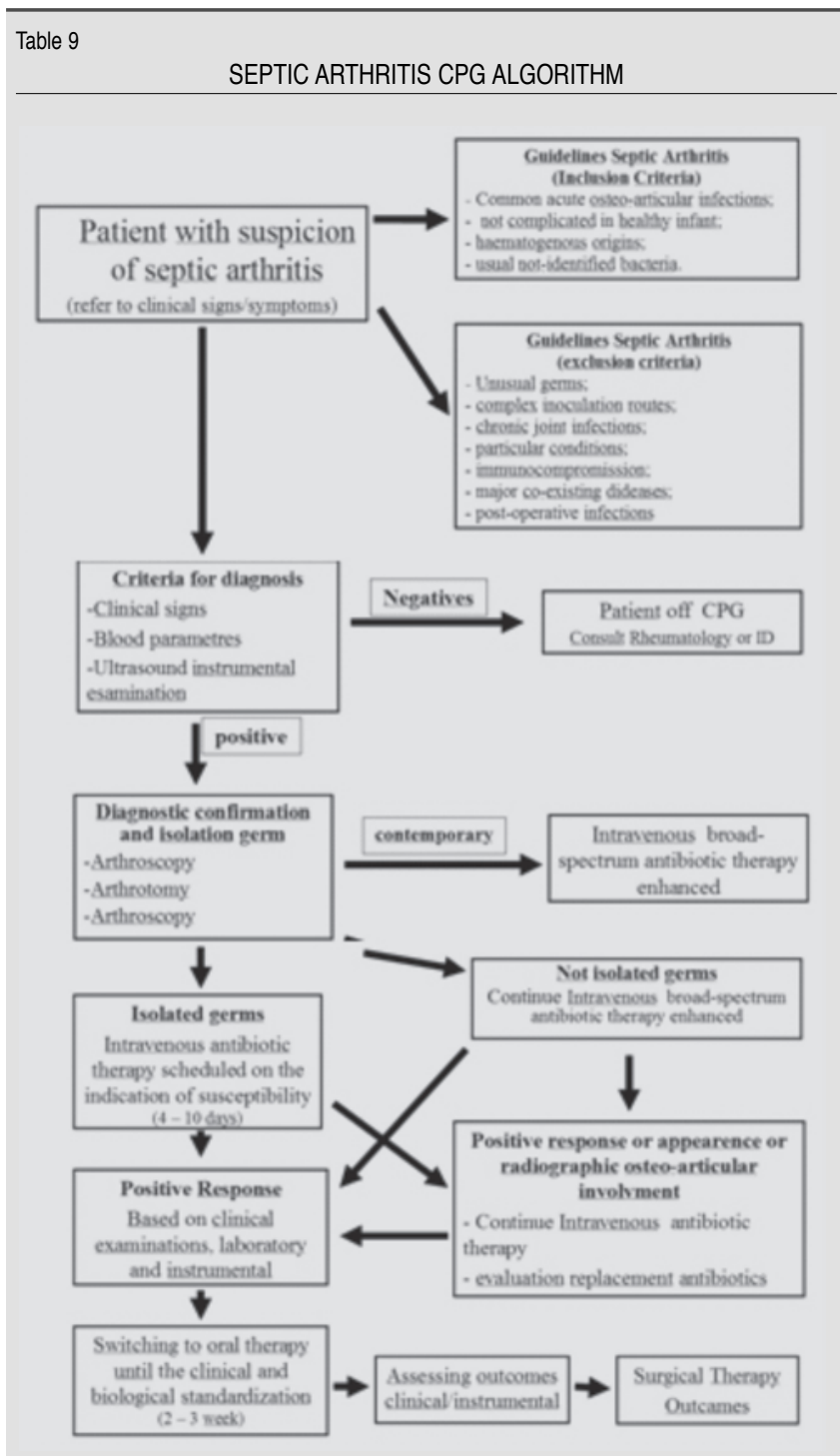

Candida albicans, particularly in intensive care, in malnourished infants or in parenteral nutrition after a gastro-intestinal tract intervention.

Rarely Proteus, Escherichia coli, Pseudomonas, Klebsiella, meningococci, enterococci, etc. (Table 5) can be isolated. ${ }^{12,21-23,43}$

If the responsible germ is identified, an intravenous antibiotic therapy will be scheduled on the indication of susceptibility and continued for 4-7 days (Table 6) if, as often happens, the germ is not isolated, we will continue an intravenous broad-spectrum antibiotic therapy enhanced or modified if we don't get a positive response (Table 7). ${ }^{13,37}$

Assessment of a therapeutic response: Even in this case the parameters to take into consideration are clinical, laboratorial and imaging. After 3 and 7 days a clinical and biological balance will be achieved. The improvement in symptoms, the value of CRP and ESR are good indexes of a response to therapy.

As regards the instrumental balance, according to some authors, the first radiographic signs may appear after only 24-48 hours, but most of the authors argued that they appear between 4 and 10 days. The early radiographic signs may have hard evidence. A first sign is the soft-tissue edema associated with a disappearance of muscular physiological interstices, later to a swelling of periarticular soft tissue and the presence of an eccentric head of the femur in hip due more to reflected muscle contracture of the adductors than to endoarticular effusion. After 8-10 days the signs appear such as geodes metaphyseal bone sign of local interests, more or less complete disappearance of the epiphyseal nuclei and periosteum detachment, sometimes significant in the infant. In older children the first radiographic signs stand out more late (10-15 days).

In relation to the possibility of multiple asymptomatic outbreaks we need for infants a complete radiographic systemic osteo-articular examination on day 15.

CT and MRI may have an important role in defining the involvement of both bone and cartilage epiphysis in the evolution of physical outcomes. ${ }^{15,18}$

Depending on the appearance or absence of radiographic signs, clinical and laboratorial response, intravenous antibiotics duration may vary according to different authors from 4 to 10 days. It will follow an oral antibioticoterapy duration of $2-3$ weeks until the normalization of serological data.

Outcomes: After a treatment well conducted in emergency, outcomes are rare. Wang ${ }^{41}$ reported the risk factors related to age, location, serology if much altered, the aggressiveness of the germ and the beginning of treatment (Table 8). The outcomes can be represented by epiphyseal, physeal, and metaphyseal alterations. ${ }^{15,26,43}$ In case of epiphyseal interest we can get even to an epiphyseal extended necrosis and a dislocation of the hip. If the growth of the cartilage is involved, it can develop some asymmetric epiphysiodesis which can lead to osteoarticular deformities or, if it is involved, all the physis can lead to remarkable shortenings of the interested bone. ${ }^{2,25,38}$ 
There were many classifications of outcomes especially for the hip and the knee.

At the same time, many interventions have been proposed for their correction (Table 9). ${ }^{4}$

All these actions can admit some shared indications or not, but all the authors agree on the necessity to

- proscribe an equalization of limb lengthening on an unstable hip

- avoid attempts to delay surgical reduction of the hip

- not to carry out arthrodesis, for the advent of prosthesis.

- not to make a joint mobilization under general anesthesia.

\section{Conclusions}

The frequency and severity of outcomes, and the therapeutic difficulties that they show, once more underline the importance of urgency in the empirical antibiotic therapy and the evacuation of joints, which remain the key pillars of the treatment of septic arthritis.

The gold standard we should aim at is to obtain a mobile and indolent joint even if not perfectly stable in the case of the hip.

\section{References}

1 Azoulay R, Alison M, Sekkal A, Sebarg G, Adamsbaum C (2007) Imagerie des infections ostéoarticular de l'enfant. Imaging of child osteoarticular infections. Arch de pédiatrie 113-121.

2 Bollini G., Cottalorda J., Jouve J.L., Laville J.M., Jacquemier M., Tallet J.M., Bouyala J.M. Séquelles des infections de la hanche et leurs traitments. Chirurgie et Orthopédie de la hanche chez l'enfant. Editions Sauramps Médical, Montpellier 1991: 169-186

3 Caksen H, Oztürk MK, Uzüm K, Yüksel S, Ustünbaş HB, Per H (2000) Septic arthritis in childhood. Pediatr Int 42(5):534-40.

4 Catagni MA, Guerreschi F, Cattaneo R (1998) Trattamento degli esiti dell'artrite settica dell'anca nel neonate e nel bambino con la metodica di Ilizarov. Rivista Italiana di Traumatologia e Ortopedia Pediatrica. Atti del VIII Corso Nazionale di aggiornamento S.I.T.O.P., 2/3-10-98, 181-191.

5 Ceroni D, Regusci M, Pazos J, Dayer R, Kaelin A (2003) Infections ostéoarticulaires aigues de l'enfant et fièvre persistante. Rev de Chir Ortho 89:250256

6 Chang WS, Clin NC, Chi H, Li WC, Huang FY (2005) Comparison of the characteristics of culture-negative versus culture positive septic arthritis in children. J Microbiol Immunol Infect 38:189-93

7 Chen MK, Wang CC, Chu ML, Pan TM, (1999) Prospective surveillance of children with invasive Haemophilus influenza disease in Taiwan. J Microbiol Immunol Infect 32:257-60

8 Chung SMK (1976) The arterial supply of the developing proximal end of the human femur. J Bone and Joint Surg 58(A):961

9 Dahl LB, Hoyland AL, Dramsdahl H, Kaarsen PL (1998) Acute osteomyelitis in children: a population-based retrospective study 1965 to1994. Scand J Infect Dis 30:573-577

10 De Boeck H (2005) Osteomyelitis and septic arthritis in children. Acta Orthop Belg 71:505-515
11 De Sanctis N, Guida P, Prevedello GF, Nunziata Rega A (1998) Le artriti settiche del ginocchio. $8^{\circ}$ Corso Nazionale aggiornamento Società Italiana Di Ortopedia e Traumatologia Pediatrica. Orta San Giulio 2-3 Ottobre 1998. 193-202

12 Ferroni A (2007) L'épidémiologie et diagnostic bactériologique des infections ostéoarticulaires aigues de l'enfant. Arch Pediatr 14:S91-S96

13 Grimprel E, Lorrot M, Haas H, Pinquier D, Parez N, Ferroni A, Cohen R (2008) Infections ostéoarticulaires: proipositions thérapeutiques du Groupe de Pathologie Infectieuse Pédiatrique (GPIP) de la Societé Française de Pédiatrie. Archives de Pédiatrie 15:74-80

14 Gutierrez K (2005) Bone and joint infections in children. Pediatr Clin N Am 52:779-94

15 Jaramillo D, Treves ST, Kasser JR, Harper M, Sundel R, Laor T (1995) Osteomyelitis and septic arthritis in children: appropriate use of imaging to guide treatment. AJR Am J Roentgenol 165(2):399-403. Review.

16 Kocher MS, Mandiga R, Murphy JM, Goldmann D, Harper M, Sundel R, Ecklund K, Kasser JR (2003) A clinical practice guideline for treatment of septic arthritis in children: efficacy in improving process of care and effect on outcome of septic arthritis of the hip. J Bone Joint Surg Am 85(6):994-9.

17 Le Saux N, Howard A, Barrowman NJ, Gaboury I, Sampson M, Moher D (2002) Shorter courses of parenteral antibiotic therapy do not appear to influence response rates for children with acute hematogenous osteomyelitis: a systematic review. BMC Infect Dis 14:2-16. Review.

18 Lee SK, Suh KJ, Kim YW, Ryeom HK, Kim YS, Lee JM, Chang Y, Kim YJ, Kang DS (1999) Septic arthritis versus transient synovitis at MR imaging: preliminary assessment with signal intensity alterations in bone marrow. Radiology 211(2):459-65.

19 McGoldrick F, Bourke T, Blake N, Fogarty E, Dowling F, Regan B (1990) Accuracy of sonography in transient synovitis. J Pediatr Orthop 10(4):501-3.

20 Mininder S, Kocher MD, Rahul Mandiga MPH, Murphy JM, Goldmann MSD, Harper MA (2003) Clinical practice guideline for treatment of septic arthritis in children. Journal of bone and joint surgery incorporated 994-999

${ }_{21}$ Morrissy RT, Haynes DW (1989) Acute haematogenous osteomyelitis: a model with trauma as an etiology. J Pediatr Orthop 9(4):447-56.

22 Novati GP, Nocivelli P, Capilupi B L'osteoartrite acuta dell'anca nel lattante. SITOP

23 Novati GP, Olappi G, Cornaglia A, Patelli A L'osteoartrite acuta nel lattante. Rivista Italiana di Traumatologia e Ortopedia Pediatrica.

24 Nunn TR, Cheung WY, Rollinson PD (2007) A prospective study of pyogenic sepsis of the hip in childhood. The Journal of Bone and Joint Surgery $100-106$

25 Peretti G (1998) Osteoartriti dell'anca nel neonato e nel bambino. $8^{\circ}$ Corso Nazionale aggiornamento Società Italiana Di Ortopedia e Traumatologia Pediatrica. Orta San Giulio 2-3 Ottobre 1998 157-166

26 Peters W, Irving J, Letts M (1992) Long-term effects of neonatal bone and joint infection on adjacent growth plates. J Pediatr Orthop 12(6):806-10

27 Rasmont Q, Yombi JC, Van der Linden D, Docquier PL (2008) Osteoarticular infections in Belgian children: a survey of clinical, biological, radiological and microbiological data. Acta Orthop Belg 74(3):374-85

28 Riebel TW, Nasir R, Nazarenko O (1996) The value of sonography in the detection of osteomyelitis. Pediatr Radiol 26(4):291-7

29 Schenk RK, Wiener J., Spiro D. Fine structural aspects of vascular invasion of the tibial epiphyseal plate of growing rats. Acta Anat 691968

30 Stott NS (2001) Review article: Paediatric bone and joint infection. J Orthop Surg 9(1):83-90

31 Trueta J (1957) The normal vascular anatomy of the human femoral head during growth. J. Bone and Joint Surg 39(B):358 
32 Trueta J (1959) The three types of acute haematogenous osteomyelitis: a clinical and vascular study. J Bone Joint Surg 41(B):671-680

33 Trueta J (1968) Studies of development and decay of the human frame. Heinemann Medical, London

34 Trueta J, Harrison MHM (1957) The normal vascular anatomy of the human femoral head during growt. Journal Bone Joint Surgery 39(B):358

35 Trueta J, Morgan JD (1960) The vascular contribution to osteogenesis. I. Studies by the injection method. Journal Bone Joint Surgery 42(B):97

36 Tudisco C, Farsetti P., Gatti S, Ippolito E (1989) Le osteomieliti croniche. L'evoluzione a distanza di 37 casi. Giornale Italiano di Ortopedia e Traumatologia, XV, 533-538

37 Utili R (2001) Gram-positive bacterial infections resistant to antibiotic treatment. Ann Ital Med Int 16(4):205-19

38 Valdiserri L, Di Gennaro GL (1998) Le sequele delle infezioni dell'anca e il loro trattamento. $8^{\circ}$ Corso Nazionale aggiornamento Società Italiana Di
Ortopedia e Traumatologia Pediatrica. Orta San Giulio 2-3 Ottobre 1998 167-179

39 Van den Bruel A, Bartholomeeusen S, Aertgeerts B et al (2006) Serius infections in children: an incidence study in family practice. BMC Family Pratice 7-23

40 Wang CH, Lin TY (1996) Invasive Haemophilus influenza diseases and purulent meningitis in Taiwan. J Formos Med Assoc 95:599-604

41 Wang CL, Wang SM, Yang YJ, Tsai CH, Liu CC (2003) Septic artrithis in children: relationship of causative pathogens, complications and outcome. J Microbiol Immunol Infect 36:41-6

42 Whalen JL, Fitzgerald RH, Morrissy RT (1998) A histological study of acute haematogenus osteomyelitis following physeal injuries in rabbits. J. Bone Joint Surgery 70(A) 1383

43 Yuan HC, Wu KG, Chen CJ, Tang RB, Hwang BT (2006) Characteristics and outcome of septic arthritis in children. J Microbiol Immunol Infect 39(4):342-7 